$11-2015$

\title{
Behavioral response to threat (BRTT) as a key behavior for sexual assault risk reduction intervention: A critical review
}

\author{
RaeAnn E. Anderson \\ University of North Dakota, raeann.anderson@UND.edu \\ Shawn P. Cahill
}

How does access to this work benefit you? Let us know!

Follow this and additional works at: https://commons.und.edu/psych-fac

Part of the Psychology Commons

\section{Recommended Citation}

RaeAnn E. Anderson and Shawn P. Cahill. "Behavioral response to threat (BRTT) as a key behavior for sexual assault risk reduction intervention: A critical review" (2015). Psychology Faculty Publications. 5. https://commons.und.edu/psych-fac/5 
Behavioral Response to Threat (BRTT) as a Key Behavior for Sexual Assault Risk Reduction Intervention: A Critical Review

\author{
RaeAnn E. Anderson*1,2 \& Shawn P. Cahill ${ }^{1}$ \\ University of Wisconsin-Milwaukee
}

*corresponding author: 144 Kent Hall, Psychological Sciences, Kent State University, Kent, OH 44240

330-672-3158 (phone),330-672-3786 (fax), ander569@uwm.edu or rander52@kent.edu 


\begin{abstract}
Despite extensive research on sexual assault, study of the processes and behaviors central to responding to sexual assault threats is limited. The purpose of this paper is to provide a critical, narrative review of the literature on behavioral response to threat (BRTT) highlighting BRTT BR TT as mechanism of self-defense interventions and process of sexual victimization. Empirical findings regarding measurement styles, effectiveness of different styles of BRTT, and facilitators and barriers of BRTT, are reviewed. Most individuals engage in some type of active behavior when faced with a sexual assault threat; yet, the range of the behaviors listed can be broad and is not well captured by current measurement approaches. Assertive BRTT is the most effective response style, but few, if any, feminist self-defense interventions studies measure change in his behavior as a result of intervention. Recommendations for clinical practice include developing comprehensive measurement of BRTT and adapting interventions to decrease barriers to assertive BRTTs. Recommendations for future research include undertaking with qualitative and quantitative efforts to better characterize the range, stability, and predictors of all possible BRTT styles.
\end{abstract}




\section{Highlights:}

1. Integrates the available research on behavioral response to threat.

2. Behavioral responses can range broadly but are rarely assessed comprehensively.

3. Effective behavioral response is affected by a number of psychological factors.

4. Behavioral response is one of the core mechanisms of self-defense interventions.

5. Future sexual assault risk reduction programs should assess behavioral response. 
Behavioral Response to Threat (BRTT) as a Key Behavior for Sexual Assault Risk Reduction Intervention: A Critical Review

\section{Significance}

Approximately $11-18 \%$ of women in the general population experience rape in their lifetimes, and this rate is higher among women on college campuses (Gross, Winslett, Roberts, \& Gohm, 2006; Post, Biroscak, \& Barboza, 2011). Most sexual assaults (90\% or greater) are committed by someone known to the victim or survivor rather than a stranger (Tjaden \& Thoennes, 2000). Sexual assault, a broader term that includes rape and other forms of sexual coercion, is associated with a vast array of deleterious consequences ranging from poorer physical health and increased rates of psychopathology to greater unemployment rates (Martin, Macy, \& Young, 2011; Schnurr, Green, \& Kaltman, 2007; Thompson et al. 2003). For an estimated 12\% of the general population, the experience of sexual violence is repeated, which further worsens outcomes (Kimerling, Alvarez, Pavao, Kaminski, \& Baumrind, 2007). Sexual assault is a decidedly gender-based issue, with women being more likely to experience sexual victimization, and men being more likely to perpetrate sexual victimization; following, this paper focuses on women's experiences of victimization consistent with the available literature and encourages future research to investigate the issues raised herein across genders (Tjaden \& Thoennes, 2000). Even though the experience of sexual violence is relatively common and associated with many physical and mental health problems, there are few efficacious interventions to prevent sexual violence. The most efficacious options, such as feminist self-defense, have generally demonstrated low efficacy in reducing sexual violence with an average effect size of 0.1 (see: (Anderson \& Whiston, 2005) with few exceptions (see: Senn et al., 2015). Increasing the efficacy of these programs may be difficult due to limited research and understanding of the 
mechanism(s) of sexual victimization. These interventions are often constrained by time and limited assessment of intervention targets (e.g., threat perception, assertive behavior, etc.), which thereby stunts further intervention refinement and development. The goal of this review is to synthesize the literature on one possible mechanism of these interventions and of sexual victimization, behavioral response to threat, in order to improve the understanding and development of sexual assault risk reduction interventions. This paper will focus on processes specific to sexual assault by acquaintances as these assaults are perceived differently than threats from strangers (VanZile-Tamsen, Testa, \& Livingston, 2005)

\section{Behavioral Response to Threat}

Research has begun to focus on possible internal mechanisms of sexual victimization (rather than external mechanisms, such as proximity to potential perpetrators) in order to better understand the psychological mechanisms and thus, better inform intervention. A psycINFO search conducted by this author for mechanism of sexual victimization revealed at least fifteen different proposed variables indicating the great range of possible explanatory variables and models. Theoretically and empirically driven research has indicated that the perception of sexual assault threats and the following response to threats are core processes and may be the core internal processes occurring during sexual victimization (Messman-Moore \& Long, 2000; Grych \& Noll, 2012).Indeed, Messman-Moore \& Long (2000) suggest that most variables linked to victimization and revictimization, such as alcohol consumption, can be best explained by how they either a) change threat perception or b) change threat response. As such, these are the behaviors most sexual assault risk reduction programs attempt to change (see: Senn et al. 2015) and have been recommended as the focus of intervention (Rozee \& Koss, 2001). Studies examining threat perception and threat response simultaneously have found that threat response 
has greater predictive power in predicting future sexual assaults than threat perception (Messman-Moore \& Brown, 2006). Yet, the study of threat response specifically has been limited by inconsistent terminology, varying methodology, and lack of consensus on which behaviors constitute threat responses. In this paper, the term behavioral response to threat, or BRTT, is used to describe any behavior, both verbal and nonverbal, that is elicited by the threat of sexual assault. Indeed, BRTT is a new term that attempts to highlight this set of behaviors, previously identified in a variety of ways, as a unified construct. These behaviors may be singular, such as one punch, or a sequence of multiple behaviors; thus, the abbreviations BRTT and BRTTs respectively, will both be used in this paper. Some of these behaviors have already been the focus of much research (i.e., being assertive) but less frequently has this research linked the specific behavior under study to the broader scheme of understanding the entire range of behavior elicited by sexual assault threats and influences on how people might respond to the threat of sexual assault by an acquaintance. The term BRTT and this review thus attempts to encourage research that unifies these goals. In this paper, the term BRTT encompasses both planned or active behaviors such as punching or kicking an aggressor, as well as involuntary or passive responses such as tonic immobility or waiting for outside help. The term BRTT is used rather than "behavioral resistance," as some behaviors may be produced without conscious recognition or perception of a risk. Similarly, BRTT better captures some response behaviors that may not be perceived as resistant, though they are employed as a strategic response to threat (e.g., bargaining). Across all of these scenarios, what these behaviors have in common is that they are all responses elicited by a sexual assault threat and are thus unified using the term BRTT. The term "style" is denotes a general characterization of the form of the behavior or series of behaviors that constitute a BRTT. Assertive BRTTs have been the focus of previous 
research for many years, but investigators have used different terms and conceptualizations in this work (for example: resistance, defensive coping). Thus, it is hoped that using the term BRTT in this literature review unifies existing research and propels new investigations.

With this conceptualization, BRTT encompasses a wide range of behavior, including both verbal and non-verbal or physical responses. Prior research has generally categorized women's behavioral responses to threat into dichotomous categories along two dimensions: physical/non-physical (i.e., verbal) and forceful/non-forceful (see Table 1; Ullman, 2007). For example, kicking and screaming would be classified in the following way: physically forceful and non-physically forceful, respectively. Forceful, physical BRTTs or assertive BRTTs have been the focus of much research, as this style of BRTT is the focus of most self-defense interventions.

Table 1

Common Categorization of Behavioral Responses to Threat (BRTTs)

\begin{tabular}{|c|c|c|c|}
\hline & & $\underline{\text { Dimens }}$ & : Forcefulness \\
\hline & & Forceful & Non-Forceful \\
\hline$\ddot{\overline{0}}$. & Physical & 1. Fighting, fleeing, shoving & $\begin{array}{l}\text { 3. Turning away, creating physical } \\
\text { distance, freezing }\end{array}$ \\
\hline 永 & $\begin{array}{l}\text { Non- } \\
\text { Physical } \\
\text { /Verbal }\end{array}$ & $\begin{array}{l}\text { 2. Screaming for help, } \\
\text { shouting "no", threatening }\end{array}$ & 4. Begging, pleading, reasoning \\
\hline
\end{tabular}

It is hoped that by conceptualizing these behaviors as a continuum of responses that share a common element of being elicited by threat rather than orthogonal classifications based on their form or effectiveness (as visually displayed in Table 1), a better understanding of these behaviors can be reached to inform research and intervention on sexual violence for adolescents and adults. 


\section{Existing Interventions}

Feminist self-defense interventions aim to teach at least two primary skills: recognizing a threatening situation, and behaviorally responding to it via active physical resistance; in essence, these interventions attempt to modify and enhance BRTT and implicitly or explicitly view BRTT as a mechanism of change. Indeed, (Senn et al., 2015) recently published the positive results of the largest trial of a feminist self-defense risk reduction program to date; this program, using a longer intervention period and enhancing self-defense with instruction on sexuality and relationships reduced the rate of sexual assault in the intervention group by $46.3 \%$. This program was called the Enhanced Assess, Acknowledge, and Act Sexual Assault Resistance Program, illustrating how behavioral response to threat is a key component. Yet, few intervention studies have both measured how BRTT has changed following intervention while simultaneously assessing sexual victimization. Feminist self-defense is the current gold standard for a variety of reasons. (Gidycz, Orchowski \& Edwards, 2011) One important rationale for continuing to promote feminist self-defense is because these programs have good evidence for acceptability; women who participate in self-defense risk reduction programs report signing up in order to feel more confident and assertive, and afterwards report feeling more effective at handling hypothetical threats (Hollander, 2004; 2010). There is some evidence that women who have been previously victimized are more likely to participate in self-defense and assertiveness training; thus, this type of intervention is perhaps appealing to one of the most at-risk groups (Brecklin, 2004). Given these data, there is ample evidence to suggest that investment in increasing the efficacy and understanding of the mechanisms of self-defense risk reduction programs is worthwhile. This is not to suggest that efforts to engage men in prevention are not also worthy; rather, these can be conceptualized as two concurrent pathways toward reducing sexual violence. 


\section{BRTT as a Key Mechanism}

One way to improve the efficacy of risk reduction programs lies in parsing the effects of individual components of the interventions and focusing on the hypothesized key behaviors and/or behavioral processes, such as BRTT. Self-defense interventions have targeted assertive BRTTs, as the effectiveness of this type of response was identified in early research on rape; active, physical responses to the threat of rape, like shouting and physically fighting, are associated with fewer completed rapes (Bart \& O'Brien, 1984; Clay-Warner, 2002; Fisher, Daigle, Cullen, \& Santana, 2007). Even though being able to produce an assertive BRTT is one of the main goals of feminist self-defense, and is hypothesized to be the "active ingredient" or mechanism of this intervention, this has never been demonstrated empirically through measuring BRTT and sexual victimization simultaneously pre- and post-intervention. Additionally, no component analysis or dismantling studies have been conducted to examine which aspects of self-defense interventions are effective for which protective processes or behaviors. For example, few studies have tested women's physical competence in self-defense skills or BRTT after intervention, and none were identified that also measured victimization outcomes over time (example: Ozer \& Bandura, 1990). This lack of measurement of BRTT, in spite of increasing assertive BRTTs as the target behaviors of self-defense interventions, holds back scientifically driven improvement to this intervention by limiting the knowledge of the mechanism and target behavior. Explanations of sexual assault risk reduction interventions from the mechanistic level are critical to enable the creation of effective programs that reduce the risk of sexual assault and can be tailored to accommodate individual needs in order to empower women who opt to reduce their risk. Following the goals of improving sexual assault risk reduction intervention programs by emphasizing understanding BRTT as a key behavior in self-defense interventions, this paper 
seeks to examine the empirical support for BRTT as a key process in sexual assault risk reduction and behavior for intervention. Through narrative review, this paper will synthesize the fragmented research on this topic, highlight critical findings, and recommend areas for future research and treatment development.

\section{Literature Review}

\section{Overview and Approach}

BRTT follows risk perception in the complex and iterative process of coping with the threat of sexual assault from an acquaintance (Nurius \& Norris, 1995). This paper will focus on BRTT in the context of acquaintance assaults as these are the most common scenarios and the topic of most research. This review will also focus on internal factors (recognizing risk, responding to risk) rather than situational factors (avoiding dangerous neighborhoods) as internal factors are the focus of current sexual assault risk reduction interventions. For most individuals the threat of sexual assault generally elicits active behavior rather than tonic immobility; however, there is a very broad range of behaviors elicited, and the form or style of these behaviors is influenced by internal (i.e., psychological factors) as well as external (i.e., the setting of the attack). This paper will review the data on BRTT in acquaintance sexual assault in five areas, each being identified as critical for understanding BRTT as a mechanism of psychological change and important for intervention development: styles of BRTTs, facilitators and barriers to specific styles of BRTTs, effectiveness of styles of BRTT, theories of sexual victimization as they pertain to BRTT, and BRTT as a potential mechanism of sexual victimization. Literature was identified by searching keywords like "rape", "sexual assault", "self-defense", "response", "assertion" and bibliographic lists obtained from pertinent articles using the psycINFO and googlescholar databases. Literature was identified following these 
searches and then grouped thematically by the author into the aforementioned areas after an indepth review.

\section{Measurement and Styles of BRTT}

Although assertive BRTTs are easy to recognize and the most effective form of behavior in terms of reducing risk, it is worthwhile to know about the entire spectrum of behavior that may be elicited by sexual assault threats. However, it has been difficult to establish what the spectrum of behavior may be given the predominating, though necessary, focus on assertive behavior in existing research. There are few standardized assessments of BRTT; some research has utilized checklists, post-hoc categorization of checklists, or formal questionnaires whereas others have utilized observer ratings of laboratory scenarios. In many cases, researchers seem to have generally created their own measure or used a checklist of behavior. The epidemiological data cited by Clay-Warner exemplifies a common approach. In this study it is unclear how the checklist of different possible protective actions was developed in the original data collection; as an author of a secondary data analysis Clay-Warner then re-coded the list into thematically designated categories based on previous research such as (Ullman, 2007).

This author was able to identify two standardized questionnaire assessments of a range of BRTTs; of note, research focusing on assertive behavior exclusively frequently uses standardized assessments. The Victim Response Strategies portion of the Sexual Experiences Interview (Levine-MacCombe \& Koss, 1986) and the Behavioral Response Questionnaire by (Nurius, Norris, Young, Graham \& Gaylord, 2000) are unique in measuring both overtly assertive behavior and non-assertive behavior (pleading, crying, no response) in relation to a sexual assault threat. 
The Victim Response Strategies measure, called in later research the Response Questionnaire (RQ) uses an interview format to collect information on both the specific strategies used to resist the sexual assault threat as well as how participants perceived the effectiveness of their resistance and the number of different forms of resistance utilized. In the original form surveyed the following ten behaviors: reasoning, pleading, turning cold, quarreling, crying, screaming for help, physically struggling, running away, no outward resistance, and other. A benefit of the RQ compared to a checklist of behavior is the rating of perceive effectiveness and number of responses used. Later research has used modifications of the RQ as a questionnaire rather than an interview. For example, Gidycz, Van Wynsberghe \& Edwards (2008) asked participants to rate eight RQ items as to the likelihood they would used that form of resistance. Modifying an existing scale for the unique purposes of a single study is a common approach in the literature that examines resistance or behavioral responses to threat. However, the drawback to this approach is the inability to compare data across studies. Additionally, this measure illustrates one of the conceptual challenges in this area of research. As shown, the RQ collected information on a variety of behavior and conceptualized all these behaviors as strategic resistance. However, some RQ items such as "no outward resistance" may reflect a desire to resist but inability to do so, such as tonic immobility that sometimes, though rarely, occurs in the presence of extreme fear.

The most comprehensive questionnaire assessment of behavioral response to threat is the Behavioral Response Questionnaire (BRQ). The BRQ characterizes BRTTs into three general styles based on factor analysis: assertive, diplomatic, and immobile (Nurius, Norris, Young, Graham \& Gaylord, 2000). This characterization has been used frequently in research and adequately represents at least a large part of the range of BRTT. Using the BRQ, participants rate 
all possible behaviors in terms of similarity to their own response; these responses are then summed for each style, allowing for a more complex and dimensional approach to evaluating BRTT, see Figure 1.

\section{Figure 1}

\section{Alternative Dimensional Characterization of BRTT}

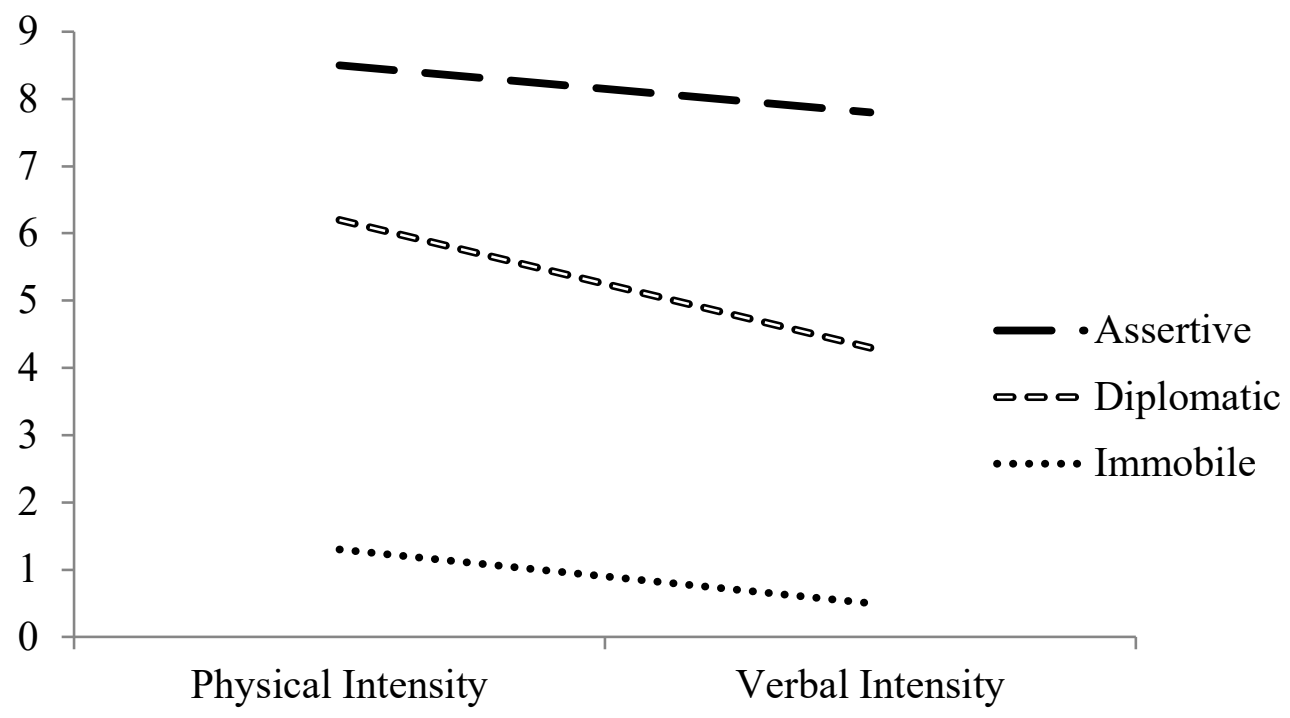

The BRQ defines diplomatic responses as an approach that attempts to accommodate the perpetrator in some way (emotionally, socially, etc.) and a relative indirectness in the way protective behaviors are presented (e.g., through joking or changing the subject). This lies in contrast to assertive responses, which directly prioritize the target of victimization's needs. Both diplomatic and assertive responses appear to be planned behaviors, whereas immobile behaviors encompass both the unconscious "freeze" responses as well as crying, which may or may not be consciously produced. Examining Table 1, assertive behaviors as conceptualized on the BRQ would generally correspond to forceful physical or verbal behaviors like those listed in quadrants 1 and 2, but diplomatic and immobile responses are less easily matched. Diplomatic responses such as "jokingly told him he was coming on too strong" seem to correspond to non-forceful, verbal behaviors (quadrant 4). Other behaviors, like "shrugged or turned my body away" along 
with behavior the BRQ would characterize as immobile, such as "started tearing up or crying" correspond to non-forceful physical behaviors (quadrant 3). Notably, the BRQ characterizations were created using factor analysis, making the BRQ is thus the most empirically supported measure of behavioral responses.

In contrast to using a questionnaire, some research teams have opted for enhancing ecological validity by using coder ratings of role-play behavior to assess BRTT. Jouriles, Rowe, McDonald, Platt \& Gomez (2011) elicited BRTT from participants in a virtual reality role play scenario and used six items to code specifically for assertive behavioral responses. Coders rated confidence in tone of voice, assertiveness, use of active resistance, passive, resistance, requests for new behavior and removal from the situation as facets of assertive behavioral response. This approach has the benefit of rating actual behavior rather than hypothetical or past behavior as a questionnaire would elicit. This approach also allows for researchers or clinicians to focus on specific behavior that is the focus of change; yet, this is also a drawback of this approach in that coding the entire range of possible behaviors for a comprehensive assessment would be extremely time intensive and requires researchers to already know which behaviors should be of focus.

In this regard, qualitative research can be of great use in examining what the range of behaviors may be. For instance, Masters, Norris, Stoner \& George (2006) conducted one of the first qualitative studies to focus on the entire spectrum of possible responses women consider. In this study 371 community women were asked to read a vignette and imagine themselves as the woman in the vignette. At the end of the vignette, the man is forcing himself on top of the woman and verbally threatening her; at this point, participants were asked to answer, in writing, "how does it end?" Behaviors that could be classified as assertive were the most commonly 
identified theme in the written hypothetical responses, accounting for $71 \%$ of the first behaviors women described but a variety of other themes were described as well. These included: excuse making, bargaining, freezing, pleading, arguing, and "going along with it." These non-assertive responses accounted for $29 \%$ of the first hypothetical behaviors described by women, indicating that a significant minority of women considers these types of responses as their first line of defense or first option. It is worth noting that this number is similar to the approximately $35 \%$ of women in epidemiological studies categorized as "no response." It is especially remarkable that so many participants opted for non-assertive strategies given the relatively extreme nature of the threat that was presented. Specifically, the stimulus given was the woman in the story repeatedly saying no and the man continuing to force himself on top of her, “... I know you want me too. We're gonna do it now, you little tease." (Masters et al. 2006, p. 294).

This finding, that significant numbers of individuals hypothetically describe non-assertive responses, was replicated in another qualitative study by Anderson, Brouwer, Wendorf \& Cahill, (in press). This study also found a number of non-assertive themes in participants' hypothetical responses to a threat, including: compliance/acceptance, awaiting further information or action to respond, and avoidance. Indeed, one quarter of participants described compliance/acceptance although it is unclear from this study what participants' motives were in utilizing this hypothetical behavior - did they not recognize the situation as threatening or feel there was no reasonable means of resistance? Additionally, most participants described more than one type of behavior, and sometimes described assertive and non-assertive forms of behavior in the same response.

These qualitative studies highlight the complexity of engaging in a BRTT for those threatened as well as the difficulty in measuring this behavior. For example, behaviors such as 
planned passivity, where a person may purposefully and strategically be passive (i.e., pretend to be asleep so he goes away; "play along" until the moment to escape) are not captured by the current classification schemes (see Table 1), but these non-assertive behaviors may be relatively common as the aforementioned qualitative research documents. Although this style of BRTT would appear undesirable, these non-assertive behaviors/styles of engagement may be justified in some circumstances depending on the values and expectations of the individual and the specific unwanted advance or aggressive act; controlling for the intensity of the threat that elicits the BRTT is critical in understanding the context of the response and its likely effectiveness.

Epidemiological and qualitative research has demonstrated that approximately one third of women surveyed did not report engaging in any kind of behavioral response when faced with sexual assault threats, as measured by checklists of behaviors (Clay-Warner, 2002). When participants report not engaging in any kind of response, it is often unclear whether these responses constitute planned passivity and/or compliance, an inability to undertake a planned response, e.g., a tonic immobility or incapacitated response, or simply a mismatch between the quantitative instrument being utilized to record responses and the individual's response. An additional complexity in measurement is the number and sequence of BRTTs. One study found that thirty-five percent of women who reported an attempted or completed rape utilized multiple behavioral strategies in their response to the threat (Clay-Warner, 2003). It may be that certain behaviors precede others and increase their effectiveness, but this interactive dynamic is difficulty to capture in a questionnaire. Indeed, Tark \& Kleck (2014) note that many of the inconsistencies in past literature on the efficacy of specific BRTTs may be "attributable to the failure...to establish the sequence of protective actions and injury" as well as difficulties related to "the use of limited two- or three-category typologies of resistance actions" (pp. 271, 272). 
Yet, neither the common categories displayed in Table 1 or the most comprehensive measure of BRTT, the BRQ, capture all of the responses highlighted in recent qualitative research (Anderson et al. in press; Masters et al. 2006). Future research into the entire range of BRTTs that could be elicited by sexual assault threats and innovative ways to capture the sequence and interaction of BRTTs is strongly recommended.

\section{Effectiveness of BRTTs}

With the ultimate goal of reducing the incidence of sexual assault, scholars and practitioners need to know what type of responses are effective in deterring further aggression when a threat has occurred. Another element of effectiveness can be avoiding injury and is an oft cited concern for reasons to not engage in a BRTT. However, this will not be a focus in this paper as epidemiological research indicates that the likelihood of experiencing a serious injury while resisting or engaging in an assertive BRTT is low (Tark \& Kleck, 2014). Indeed, when injuries occur it tends to be before a BRTT has occurred and the risk of injury after BRTT was similar when compared to incidents in which no action was taken (Tark \& Kleck, 2014). Early research based on interviews with women who experienced attempted or completed rape found that those who escaped rape after a threat used a greater number of strategies and tended to utilize physical force in their response (Bart \& O’Brien, 1984). This finding has since been replicated in many studies; people who respond in an active, physical manner are less likely to experience completed rape (Ullman, 2007). However, it is also necessary to know how variations in environmental circumstances, the sequence of threats and corresponding BRTTs, et cetera, may impact effectiveness.

Clay-Warner (2002) investigated how BRTTs may vary due to situational factors among participants who experienced attempted and completed rape in the National Crime Victimization 
Survey (NCVS). This study used the following three classifications to group BRTTs: physical actions, including both forceful and non-forceful (fighting back, fleeing); forceful verbal (screaming, threatening); and non-forceful verbal (reasoning, pleading, appeasing). Only one situational variable was found to be related to differences in BRTT utilized: relationship to the perpetrator. Clay-Warner (2002) found that non-forceful verbal BRTTs were used more when participants were attacked by someone they knew; notably, the vast majority of assaults are perpetrated by someone known to the victim (Tjaden \& Thonnes, 2000). Physical BRTT was the only strategy that predicted rape avoidance, and non-forceful verbal responses were associated with a twofold increase in completed rape. This study demonstrates the poor outcomes and dangers when the aforementioned barriers to protective BRTT are not overcome. To reiterate, when faced with an attacker they know, the most common sexual assault threat, participants in this study more often utilized less effective non-forceful strategies, which was then associated with a greater likelihood of completed rape.

These issues were further examined in a follow-up study; this analysis utilized three mutually exclusive categories for the type of BRTT employed: physical BRTT (60\%), no BRTT (22\%), and verbal only BRTT (18\%) (Clay-Warner, 2003). Physical BRTT was the most common (60\%) followed by no BRTT (22\%) and verbal only BRTT (18\%). There were relatively few predictors of BRTT style; women who were attacked at night were more likely to use verbal BRTT. What was most notable in this study was the lack of predictors related to environmental characteristics, indicating that psychological barriers may be far more influential than situational ones. Fisher, Daigle, Cullen \& Santana (2007) made a notable contribution in examining the effectiveness of different BRTTs for different types of sexual victimization, including rape, sexual coercion (sexual acts achieved through tactics other than physical force, 
such as threats), and unwanted sexual contact. This work is unique, as almost all prior research focused on responses to rape exclusively. This study utilized the four major categories outlined in Table 1 for classifying BRTTs, and used the National College Women's Victimization Survey as their data source. Similar to Clay-Warner's research, this study found that $37 \%$ of participants utilized more than one BRTT, and that the severity of the attack was positively associated with a greater number of BRTTs. Twenty four percent of women who experienced sexual coercion used more than one BRTT while $40 \%$ of women who experienced rape used more than one BRTT. This is consistent with experimental research that has found the intensity of the BRTT increased as the threat increased (Anderson \& Cahill, 2014; Haines Slamka, 2003). They also detected differences in the types of BRTTs utilized associated with type of victimization. For example, the majority of women who experienced sexual coercion (75\%) used non-forceful verbal BRTT, whereas this strategy was less common for other experiences. This finding is consistent with the concept of behavioral matching; when threatened verbally women response with verbal behavior. In sum, this research demonstrates that assertive, active styles of BRTT are the most effective, and diplomatic style BRTT was associated with doubling the rate of rape in Clay-Warner (2002). Yet much more information is needed, the aforementioned research demonstrates that multiple behaviors are often utilized, yet few analyses were able to control for this. The sequence of behavior may impact effectiveness; for instance, shouting "no" may be effective at the first sign of physical coercion, but not after a person has joked about his/her discomfort; current research has not yet been able to examine this issue. Similarly, behavioral matching may be dependent on the sequence of behavior. The effectiveness of assertive BRTT is also consistent with the limited research that exists from the perspective of men as potential perpetrators. One study found that 
college men rated assertive behaviors as more effective in deterring other men's advances

(Byers, Giles \& Price 1987); this is an area of research that deserves far more attention.

\section{Facilitators and Barriers to Responding}

Cognitive-ecological model theory of response to sexual assault indicates that psychological factors may facilitate or hinder certain styles of BRTT (Nurius \& Norris, 1995).

Research using this model has identified three major types of factors that influence the process of responding to sexual assault threats: background, intrapersonal (within person) and interpersonal (between person) factors.

Background factor: sexual victimization history. Experimental and quasi-experimental work utilizing vignettes has been especially fruitful in establishing the relationship between sexual victimization history and BRTT. Crawford, Wright \& Birchmeier (2008) found that women with a history of sexual victimization chose riskier behavioral response options at five of the eight decision points portrayed in a written vignette about a college party. These included relatively low risk responses, such as attending a party with strangers where alcohol was consumed, to higher risk responses, like accepting help to get to their room from a male stranger when ill from consuming alcohol at the party. Similarly, Naugle (2000) compared intended BRTTs rated after viewing three video vignettes portraying sexual assault risk. In two of the three risk vignettes, participants with a history of victimization were more likely to engage in high risk behavior such as acquiescing to coercive behavior from an authority figure. Anderson (2014) found that participants with a history of sexual revictimization were more likely to engage in diplomatic and immobile style responses to an audio vignette than women without a history of sexual revictimization. Haines Slamka (2003) found that, across three different risk scenarios, women without a history of sexual victimization were more likely to engage in active behavioral 
responses than women who had experienced sexual victimization. This research indicates that sexual victimization history is predictive of less effective BRTT, but it is unclear why.

Intra- and interpersonal factors. Less research has examined intrapersonal and interpersonal factors, but what exists has highlighted distinct predictors for different types of BRTTs. Intrapersonal factors such as feelings of sadness, embarrassment, self-consciousness, fear of rejection, increased self-blame, and less perpetrator blame have been associated with nonforceful BRTTs (Norris, Nurius \& Dimeff, 1996; Nurius, et al. 2000). In contrast, anger and less self-blame has been associated with increased assertive and physically forceful BRTTs (Bart \& O'Brien, 1984; Nurius, Norris, Macy, \& Huang, 2004). In Jouriles, Simpson Rowe, McDonald \& Kleinsasser (2014), researchers found that participants without a history of sexual victimization were more likely to express anger during a sexual assault threat presented via virtual reality than participants with a history of sexual victimization, even while controlling for assertion. This suggests that anger is a protective intrapersonal emotional response, but it is unclear what the pathway or mechanism is between sexual victimization and anger elicited by threat. Yet, this demonstrates that emotional responses can be powerful motivators of protective behavior. Other research has found that when participants perceive greater negative consequences, such as embarrassment, for not undertaking self-protective behaviors, they are more likely to take action to protect themselves (Orchowski, Untied, \& Gidycz, 2012). Interpersonal factors are less well researched but have been associated with specific BRTTs; higher relationship expectancies, relationship concerns, and a prior relationship with the perpetrator have been associated with diplomatic and non-forceful BRTTs (Macy, Nurius, \& Norris, 2006; Turchik, et al. 2007).

In addition to these retrospective questionnaire studies, a few experimental studies have been conducted, and findings have largely converged with questionnaire data. For example, 
relationship concerns are strong even in an experimentally manipulated situation; when presented with different written vignettes that portrayed relationship intimacy, participants tended to describe less assertive BRTTs and tolerate higher threats compared to vignettes with low romantic interest (Byers, Giles, \& Price, 1987; Livingston \& Testa, 2000). In Haines Slamka (2004), 139 college women were asked to read three different threatening scenarios in which unwanted sexual contact took place and rate how they would feel, think, and act in each scenario. This study found that women who were higher in trait assertion reported lower emotional (intrapersonal) barriers such as fearfulness and confused emotions. Additionally, women who had higher trait scores of sexual assertion reported more anger emotions and were more likely to report active BRTTs to hypothetical scenarios.

Interactions of factors. Research linking these areas is important for highlighting potential targets for intervention. For example, Macy Nurius, \& Norris (2006) found that a history of sexual victimization was related to intrapersonal factors including anxiety about experiencing injuries and lower confidence. Nurius, Norris, Young, Graham \& Gaylord (2000) recruited a sample of 202 college women with a history of victimization and used path analysis and regression to examine how these three types of factors -background, intrapersonal and interpersonal - interacted to influence BRTTs as measured by the BRQ. This study found that participants who tended to have greater concerns about experiencing physical injuries, fewer concerns about preserving the relationship, and increased feelings of anger were more likely to endorse assertive BRTTs. The model including these predictors accounted for $36 \%$ of the variance predicting an assertive BRTT. Significant predictors of diplomatic BRTTs were increased self-consciousness and feelings of sadness, accounting for $25 \%$ of the variance. Other studies utilizing this model or related constructs have found that high relationship expectancies 
were predictive of both diplomatic and non-forceful BRTTs (Macy, et al. 2006; Turchik, et al. 2007).

Interactions among these factors may be key to elucidating the process of BRTT and informing interventions. Macy, Nurius, \& Norris, (2007a) recruited 415 college women with histories of sexual victimization to establish empirically based risk profiles based on their responses to questionnaires about alcohol use, relationship expectancies, precautionary behaviors, and past experiences of sexual victimization. Using latent profile analysis, four multivariate risk profiles emerged: severe victimization and high relationship expectancies, severe victimization and high alcohol use, high alcohol use-low else, high relationship expectancies and high precautionary behaviors. A second study then investigated whether these profiles were associated with differential BRTT measured using the BRQ regarding a past assault (Macy, Nurius, \& Norris, 2007b). The severe victimization and high relationship expectancy group was significantly more likely to report diplomatic and immobile style BRTTs. There were no significant differences between the groups in assertive BRTTs, but the high alcohol use/severe victimization group reported the numerically lowest levels of assertive and diplomatic BRTTs. This area of research is particularly relevant for elucidating why victimization history is such a potent risk factor and how to intervene; it may be that there are differential risk profiles that can be identified empirically and matched to interventions.

In sum, factors associated with assertive/physically forceful BRTTs are: greater anger at the time of the assault, fewer concerns of injury, fewer feelings of fear and confusion, less selfblame, and fewer concerns about the relationship. Notably, fewer predictors have been identified for immobile style BRTT than for assertive and diplomatic styles even though immobile style BRTT is the style most likely to be associated with experiencing rape (see next section; Clay- 
Warner, 2002). It is unclear from this research whether factors that are facilitators or positive predictors of assertive BRTTs, such as increased anger, would reciprocally be barriers for other styles. In other words, when a factor is identified as a facilitator for one style of BRTT, is it a barrier for a different style of BRTT? This area is ripe for future research as many of the barriers identified, such as certain emotional reactions, are the focus of existing psychological interventions and may be malleable to existing intervention techniques.

\section{BRTT as an Internal Mechanism of Sexual Revictimization}

Different styles of BRTT are beginning to be distinguished, predictors of specific BRTTs are being identified, and the link between BRTT and sexual victimization history has been firmly established. Taken together, this body of literature points to BRTT as a potential mechanism for sexual assault risk reduction; less effective responses lead to increased likelihood of rape and more effective, protective responses reduce that risk. This is in fact the rationale behind most feminist self-defense risk reduction interventions. BRTT may also be a mechanism of repeated sexual victimization, in that the experience of sexual victimization and the associated negative sequelae may interfere with the ability to utilize effective BRTTs.

Using a series of vignettes $(n=40)$ and standardized behavioral response options, Yeater \& Viken (2010) found that participants with a history of victimization chose responses lower in refusal and, as the severity of the risk in the scenarios increased, the refusal level increased less compared to participants without a history of sexual victimization. This contrasts other research that has found that participants generally increase the intensity of response in accordance with the intensity of threat; this process may be different for those with a history of sexual victimization. This study is unique in illustrating, in an experimental fashion, victimization history was associated with an change in response regardless of specific vignette content, 
indicating BRTT may be a mechanism of sexual revictimization independent of other risk factors. Notably, for participants with a history of sexual victimization, the refusal responses were both lower in refusal intensity and increased in refusal intensity at a lesser rate, indicating two potential pathways through which behavioral response may operate to alter risk for sexual victimization. Another study using the same vignette series asked participants to describe in an open-ended fashion their own responses that were then rated by experts (Yeater, McFall, \& Viken, 2011). Using hierarchical linear modeling, this study found that victimization history had a moderating effect on the relationship between sexual activity, alcohol, and the effectiveness of the behavioral responses such that, as the levels of sexual activity and/or alcohol consumption increased, response effectiveness decreased.

Two studies were identified that examined the relationships between a history of sexual victimization, BRTT, and future victimization risk. These studies are notable in utilizing a prospective design to better demonstrate the potential mechanistic properties of BRTT. Gidycz, Van Wynsberghe \& Edwards (2008) asked participants to hypothetically evaluate what BRTT they would engage in at Time 1 regarding an imagined assault, and compared responses to a follow-up assessment nine weeks later to examine whether women engaged in their intended BRTT. Sixty-eight of the 424 women (16\%) were assaulted over the follow-up period, and these results indicated that immobile BRTTs during the attack were predicted by prior experiences of sexual victimization.

Messman-Moore \& Brown (2006) combined a vignette study with a prospective design to examine prior sexual victimization, risk perception, and a specific BRTT (leaving the risky situation). This study is unique in examining risk perception as well as BRTT. Outcomes were examined by groups created based on sexual victimization history: history of revictimization, 
history of adolescent or adult rape only, history of CSA only, and no victimization. Based on this grouping scheme, participants with a history of revictimization were most likely to report that they would leave the scenario at a later time, and were more likely to fall above the $70^{\text {th }}$ percentile in later leave times. During the follow-up period, participants who endorsed late leave responses were more likely to experience completed rape. This study also found that, while poorer risk perception was related to prospective revictimization, BRTT was a stronger predictor. This study is important in demonstrating a link between victimization, revictimization and less effective BRTT in a vignette, as well as how results from an analog study may be predictors of outcome. Although this study only measured one possible BRTT, it is a potentially critical behavior that may be applied to many risky situations.

The research reviewed thus far has established a link between sexual victimization history and BRTT. Fewer studies have examined these relationships prospectively; however, studies conducted by Gidycz, Van Wynsberghe \& Edwards (2008) and Messman-Moore \& Brown (2006) found that a history of sexual victimization was related to less effective behavioral responding, and less effective behavioral responding was related to future victimization. Together, these studies illustrate that less effective BRTT may be a mechanism of both victimization and revictimization. Thus, BRTT is a core behavior of interest and a potent area for intervention.

\section{Discussion}

Sexual assault is a serious threat to public health affecting many individuals with a number of negative consequences. Though there is considerable extant research on interventions, increasing the effectiveness and reach of these interventions is still needed. In order to enhance these interventions, a mechanistic understanding of their hypothesized "active ingredients" and 
measurement of these behaviors is necessary. In feminist self-defense interventions, BRTT is the target behavior, yet it is rarely measured and poorly understood as a psychological process. Research has begun to identify different styles or forms of BRTT and link these styles of psychological factors that predict their use in response to sexual assault threats. Less effective BRTT has been repeatedly linked to sexual victimization and revictimization, illustrating the critical role of this behavioral process. Following, recommendations for improving the assessment of BRTT, intervention targeting BRTT, and research on BRTT are outlined below.

\section{Assessment}

Our limited descriptions of BRTT and therefore ability to measure this construct comprehensively and reliably are likely because this behavior is thought to be difficult to elicit and evaluate in a laboratory setting. The BRQ is the most comprehensive questionnaire assessment of more than one type of BRTT that this author was able to acquire, though there may be others. Although the most empirically based tool available, the BRQ does not appear to capture all possible responses but, nonetheless, is more comprehensive than the common categorization scheme displayed in Table 1. More sensitive assessment tools are needed that capture the range of possible behavioral responses. Also important for assessment is measurement of the likelihood of or strength of engaging in each behavioral response and the sequence of responses. As illustrated by Balemba \& Beauregard (2012), the sequence of behavior can elucidate differential, multiple interactive patterns that, in their study, identified different types of perpetrators. At this time, the BRQ is recommended for research and intervention examining BRTT as it is the most comprehensive measure available. This instrument or other instruments would be strengthened by incorporating a broader range of behaviors and assessment of the sequence of behaviors. 
A key issue in the assessment of BRTT is the use of a standardized threat stimulus or stimuli. Standardization of the threat stimulus is critical for evaluating individual differences in the strength of BRTT, which often mirrors the intensity of the threat stimulus (Anderson \& Cahill, 2014; Clay-Warner, 2002). Thus, in order to provide a baseline assessment of BRTT, standardized threat stimuli are critical. Much of the past research measuring BRTT has utilized vignettes to standardize the threat stimulus, which has been undoubtedly fruitful. Intended BRTTs in reaction to a one page written vignette has been linked to future victimization (Messman-Moore \& Brown, 2006). Audio vignettes have been used to elicit behavior rated by experimenters (Anderson \& Cahill, 2014; Pumphrey-Gordon \& Gross, 2007). Virtual reality role-play has differentiated women with a history of sexual victimization from those without based on experimenter ratings of behavior (Jouriles, Rowe, McDonald, Platt, \& Gomez, 2011). Thus, a variety of options with different levels of internal validity and expense are available. Some of these approaches, like the written and audio vignettes, have even previously been adapted to include additional contextual elements with success. In one study, participants with a history of sexual victimization rated virtual reality role-plays as feeling more realistic compared with those without a history of victimization; indicating that this tool may be particularly helpful for those at most risk (Jouriles et al. 2014).

It is unclear whether the current characterizations of BRTT styles are trait-like constructs which are stable over time or are more state-like and elicited by certain characteristics of sexual assault threats, or a combination thereof. Most research examines behavioral responses through retrospective report; many times the attacks and responses recounted have taken place years earlier. It is also difficult to quantitatively analyze the sequence of events that take place during sexual assaults, and research often selects the first behavior or similar as a compromise. 
However, there is good concordance in the type of behaviors elicited by laboratory threats and the behaviors then elicited by a real life assault, indicating that analog measurement options can be fruitful (Gidycz, Van Wynsberghe, \& Edwards, 2008; Turchik \& Gidycz, 2011; Turchik, Probst, Chau, Nigoff, \& Gidycz, 2007). It is in the interest of intervention efficacy to further characterize BRTT styles, establish the stability of BRTT styles, establish whether specific risk elicit specific BRTTs, establish the most effective sequence of behavior in order to most effectively, proactively, change this behavior.

Valid assessment tools are vital for establishing empirically based risk profiles and conducting risk assessments. As demonstrated in Gidycz, Van Wynsberghe \& Edwards (2008), women who said they would engage in assertive BRTTs often did engage in assertive BRTTs when attacked during the follow-up period; simple assessments such as the one conducted in this study could also be adapted as comprehensive risk assessments to identify women in greatest need of intervention. Identifying differential risk profiles following theory is a critical step for maximizing the effectiveness and impact of efficacious interventions as they are identified. Remarkably, BRTT has never been measured in any previous sexual assault risk reduction interventions that also simultaneously measured frequency of sexual victimization, even though it is the target behavior of self-defense interventions. The lack of conjoint assessment of BRTT and sexual victimization in a self-defense intervention is comparable to not monitoring homework designed to strength the mechanism of change (exposure or cognitive restructuring) or PTSD symptoms in a PTSD intervention study and instead only measuring whether patients return to therapy. Measuring the behavior an intervention is attempting to change is critical to demonstrating the efficacy of that intervention. This illustrates one of the challenges of research 
in this area, in that even basic measurement standards and strategies have not yet been standardized and established.

BRTT should be assessed pre- and post-intervention, at a minimum, following the standards of clinical assessment as established in other intervention fields such as depression and PTSD treatment trials. Implementing pre- and post-assessment of this key behavior would allow the field to better understand the hypothesized mechanisms of these interventions and hopefully continue to improve their effectiveness. Although the occurrence of sexual assault is the ultimate dependent variable, it is difficult to develop adjunctive intervention or improve current interventions without knowledge of the mechanism of behavior change.

\section{Interventions}

Interventions for men to prevent sexual assault are sorely needed; yet, it would be unwise to disregard the volumes of research on feminist self-defense intervention, as women should be able to choose to change their own risk status. Feminist self-defense is currently the gold standard for sexual assault risk reduction; however, the efficacy of these interventions could be increased by knowing the mechanism of change. As reviewed in this paper, BRTT is likely the target mechanism in feminist self-defense interventions as well as an internal process of victimization and revictimization. Even though the ability to utilize an effective BRTT is a complicated process influenced by several factors, and there are few comprehensive measures of BRTT. Thus, any intervention designed to change BRTT must be able to measure BRTT and, to be effective, overcome the barriers to utilizing protective BRTTs (Macy et al. 2007b). Though feminist self-defense is an intuitive approach, it may be that for women at high risk for revictimization there are too many barriers for a one-time or time-limited self-defense intervention to be effective although recent trials of longer duration have shown positive results 
(Senn et al. 2015). These interventions have historically been implemented in brief, one session settings; few clinicians would ideally treat conditions related to revictimization, such as depression or PTSD in a few hours. Those self-defense interventions that do find significant results tend to be much longer; in one example of effective intervention, participants completed approximately 30 hours of just the physical training component (Hollander, 2014). The same expectation for treating the complex difficulties related to experiencing sexual victimization (i.e., depression or PTSD) may need to be adopted - we may need to expect these interventions to be longer, have multiple components in order to target multiple behaviors, et cetera in order to be more effective.

However, this may not be the case for adolescents. A recent study by Rowe, Jouriles, \& McDonald (2015) demonstrated the efficacy of a 90 minute assertive resistance program in reducing sexual victimization for adolescent girls. This is a rather remarkable finding given the inconsistent results of other brief programs. However, the innovative use of virtual reality in this intervention may have been critical; it may also be that intervening at a younger age is simply much more effective for changing the target behavior.

An example of a new approach to increase the efficacy of sexual assault risk reduction interventions for adults and incorporate knowledge of BRTT is conceptualizing emotion dysregulation as the underlying difficulty or mechanism of sexual revictimization (Walsh, DiLillo \& Messman-Moore, 2012). For example, an emotion regulation intervention for intense negative affect that leads to binge-drinking may reduce sexual assault risk for woman whose risk profile indicates emotion and alcohol consumption as relevant difficulties. This example also suggests that different levels and types of intervention may be needed for different profiles of risk. Where some individuals may benefit from a one day self-defense intervention as they 
experience few barriers to effective BRTT, others may require a multi-week intervention that targets several areas. There are existing psychotherapy models that offer flexible yet empirical approaches to individual psychopathology that could be adapted for the purpose of overcoming psychological barriers to effective BRTT and therefore reducing revictimization risk. For example, the unified protocol and dialectical behavior therapy (DBT) approaches emphasize empiricism and function of emotion, rather than diagnoses; indeed, for many patients who receive DBT childhood abuse is a significant component of the etiology of their dysfunction. Interventions like these have the benefit of already embracing a personalized approach and, thus, could be a model for adaptive interventions matched to individual risk profiles as outlined by theory.

\section{Future research}

Developmental and cultural differences. As with many behaviors, BRTT is likely influenced by developmental and cultural differences. For example, what is appropriate and/or effective for a twelve-year-old may be different than the appropriate and effective strategy for a twenty-year-old. Similarly, the cultural background and context of sexual assault threats undoubtedly influence BRTT, as gender roles are rooted in a cultural context that is not invariant. No research was identified that examined how cultural influences and context influence BRTT in the case of sexual assault; this is an important gap to address in future research.

Dimensions of effectiveness. Research on the effectiveness of behavioral responses from the perspective of potential perpetrators is sorely needed. How assertive BRTTs are perceived, how environmental factors affect perception, et cetera, may be crucial to developing effective intervention. Another area of BRTT research may be examining how the process of BRTT 
differs for men. A substantial number of young men experience sexual victimization and, following men's different gender roles in American society, BRTT may be different for young men at risk of sexual assault (French, Tilghman, Malebranche, 2015).

Theory-driven research. Finally, increased theory-driven work is strongly recommended. For example, there are a number of studies that have highlighted how common sequelae of CSA, like dissociation and PTSD symptoms, appear to be related to victimization; however, few studies have linked these symptoms to specific mechanisms of sexual victimization like BRTT. Mechanistic level explanations of distal and proximal risk factors are necessary to establish causal risk pathways for any phenomena; this may be especially important in the study of sexual victimization, as the risk factors are multiple and spread out over time. Research establishing risk profiles such as that by Macy and colleagues indicate that there is likely variation in the levels of risk women face and their ability to engage in an effective BRTT. If these multivariate profiles can be established, reliably measured, and linked to outcome, they will be critical in identifying the level of intervention individual women would most benefit from, and help allocate limited resources most effectively. Additionally, it is likely that other types of childhood abuse and maltreatment are also related to BRTT, as the interconnection among forms of abuse has been well-documented (Hamby \& Grych, 2013). It is recommended that future research examine multiple violence outcomes in assessing the efficacy of the program ((Rowe et al., 2015). Research on risk factors exists in abundance compared to research focused on how these issues apply to prevention and risk reduction through mechanisms like BRTT (Hamby, McDonald \& Grynch, 2014). 


\section{Conclusions}

Sexual revictimization affects roughly the same number of people affected by PTSD, OCD and GAD combined; even though we have multiple intervention strategies for these conditions, we have few approaches for reducing the risk of sexual victimization or revictimization (National Institutes of Mental Health, 2012). This lack of connection between the scope of the problem and the availability of interventions to reduce the occurrence of sexual assault results from the convergence of many factors, including limited understanding of the behavioral processes involved and lack of funding. In spite of BRTT being the presumed target behavior of feminist self-defense intervention; it is rarely if ever measured pre- and postintervention, likely in part due to the absence of a unified research on this concept. Experimental and analog approaches indicate that these can be utilized to measure BRTT and further research is needed to develop these approaches into standardized assessment tools. Data indicates that assertive BRTTS are commonly elicited by sexual assault threats, yet a significant number of people report not engaging in any response, or reported less typical responses not captured by current assessment tools. Both cross-sectional and experimental research indicate that assertive BRTT is the most effective response for reducing sexual assault risk, yet further research is needed on what factors facilitate this and how interventions can target these factors to increase the likelihood that an effective BRTT will be elicited when a threat is presented. Simultaneously, greater research on this topic may generate data on the dyadic process of acute sexual assault threat, which would be extremely useful for preventative interventions for men to reduce sexual aggression. Sexual victimization is strongly associated with less effective BRTTs, highlighting BRTT as a key behavior of interest. Greater research on BRTT is needed to understand this behavioral process to improve the effectiveness of sexual assault risk reduction interventions. 


\section{Acknowledgements:}

Thanks for Cory Patrick, PhD, Greer Raggio, PhD, MPH, and Cristal Weeks, PhD and my preliminary examination committee for thoughtful reviews and suggestions on drafts of this manuscript. 


\section{References}

Anderson, R. E. (2014). Not getting out while there is still time? Behavioral response to threat as a possible mechanism of sexual revictimization. University of Wisconsin-Milwaukee, Milwaukee, WI.

Anderson, R. E., Brouwer, A., Wendorf, A. R., \& Cahill, S. P. (in press). Women's behavioral responses to the threat of a hypothetical date rape stimulus: A qualitative analysis. Archives of Sexual Behavior.

Anderson, R. E., \& Cahill, S. P. (2014). Utility of the response-latency paradigm for eliciting and evaluating women's responses to the threat of date rape. Violence and Victims(29)2, 248261. doi: 10.1891/0886-6708.VV-D-12-00101R1

Anderson, L. A., \& Whiston, S. C. (2005). Sexual assault education programs: A meta-analytic examination of their effectiveness. Psychology of Women Quarterly, 29(4), 374-388. http://doi.org/10.1111/j.1471-6402.2005.00237.x

Balemba, S., \& Beauregard, E. (2012). Reactions to resistance: The role of contextual factors in sex offending. Violence And Victims, 27(2), 148-165. doi:10.1891/0886-6708.27.2.148

Bart, P. B., \& O'Brien, P. H. (1984). Stopping rape: Effective avoidance strategies. Signs, 10(1), 83-101. doi: 10.1086/494115

Brecklin, L. R. (2004). Self-defense/assertiveness training, women's victimization history, and psychological characteristics. Violence Against Women, 10(5), 479-497. doi:

$$
10.1177 / 1077801204264296
$$

Byers, E. S., Giles, B. L., \& Price, D. L. (1987). Definiteness and effectiveness of women's responses to unwanted sexual advances: A laboratory investigation. Basic and Applied Social Psychology, 8(4), 321-338.doi: 10.1207/s15324834basp0804_5 
Clay-Warner, J. (2002). Avoiding rape: The effect of protective actions and situational factors on rape outcome. Violence and Victims, 17(6), 691-705. doi: 10.1891/vivi.17.6.691.33723

Clay-Warner, J. (2003). The context of sexual violence: Situational predictors of self-protective actions. Violence and Victims, 18(5), 543-556. doi: 10.1891/vivi.2003.18.5.543

Crawford, E., Wright, M. O. D., \& Birchmeier, Z. (2008). Drug-facilitated sexual assault: College women's risk perception and behavioral choices. Journal of American College Health, 57(3), 261-272. doi: 10.3200/jach.57.3.261-272

Fisher, B. S., Daigle, L. E., Cullen, F. T., \& Santana, S. A. (2007). Assessing the efficacy of the protective action-completion nexus for sexual victimizations. Violence and Victims, 22(1), 18-42. doi: 10.1891/vv-v22i1a002

French, B. H., Tilghman, J. D., \& Malebranche, D. A. (2015). Sexual coercion context and psychosocial correlates among diverse males. Psychology of Men \& Masculinity, 16(1), 42-53. doi:10.1037/a0035915

Gidycz, C. A., Orchowski, L. M., \& Edwards, K. M. (2011). Primary prevention of sexual violence. In M. P. Koss, J. W. White, A. E. Kazdin, M. P. Koss, J. W. White, A. E. Kazdin (Eds.), Violence against women and children, Vol 2: Navigating solutions (pp. 159-179). Washington, DC, US: American Psychological Association. doi:10.1037/12308-008

Gidycz, C. A., Van Wynsberghe, A., \& Edwards, K. M. (2008). Prediction of women's utilization of resistance strategies in a sexual assault situation: A prospective study. Journal of Interpersonal Violence, 23(5), 571-588. doi: 10.1177/0886260507313531 
Gross, A. M., Winslett, A., Roberts, M., \& Gohm, C. L. (2006). An examination of sexual violence against college women. Violence Against Women, 12(3), 288-300. doi: $10.1177 / 1077801205277358$

Haines Slamka, S. J. (2003). The relationship between personal characteristics and college women's affective, behavioral, and cognitive responses to scenarios of unwanted sexual contact. 63, ProQuest Information \& Learning, US. Retrieved from https://ezproxy.lib.uwm.edu/login?url=http://search.ebscohost.com/login.aspx?direct=tru $\mathrm{e} \& \mathrm{db}=$ psyh\&AN=2003-95012-072\&site=ehost-live Available from EBSCOhost psyh database.

Hamby, S. \& Grych, J. (2013). Tracing the threads of the web: The epidemiology of interconnections among forms of violence and victimization In Hamby, S. \& Grych, J (Eds.) Web of Violence: Exploring connections among different forms of interpersonal violence and abuse (pp. 9-28) New York, NY, US: Springer Science + Business Media

Hamby, S., McDonald, R., \& Grych, J. (2014) Trends in violence research: An update through 2013. Psychology of Violence, 4(1), 1-7. doi: 10.1037/a0035384

Hollander, J. A. (2004). 'I Can Take Care of Myself': The impact of self-defense training on women's lives. Violence Against Women, 10(3), 205-235. doi:

$10.1177 / 1077801203256202$

Hollander, J. A. (2010). Why do women take self-defense classes? Violence Against Women, 16(4), 459-478. doi: 10.1177/1077801210364029

Hollander, J. A. (2014). Does self-defense training prevent sexual violence against women?. Violence Against Women, 20(3), 252-269. doi:10.1177/1077801214526046 
Jouriles, E. N., Rowe, L. S., McDonald, R., Platt, C. G., \& Gomez, G. S. (2011). Assessing women's responses to sexual threat: Validity of a virtual role-play procedure. Behavior Therapy, 42(3), 475-484. doi: 10.1016/j.beth.2010.11.005

Jouriles, E. N., Simpson Rowe, L., McDonald, R., \& Kleinsasser, A. L. (2014). Women’s expression of anger in response to unwanted sexual advances: Associations with sexual victimization. Psychology Of Violence, 4(2), 170-183. doi:10.1037/a0033191

Kimerling, R., Alvarez, J., Pavao, J., Kaminski, A., \& Baumrind, N. (2007). Epidemiology and consequences of women's revictimization. Women's Health Issues, 17(2), 101-106. doi: 10.1016/j.whi.2006.12.002

Livingston, J. A., \& Testa, M. (2000). Qualitative analysis of women's perceived vulnerability to sexual aggression in a hypothetical dating context. Journal of Social and Personal Relationships, 17(6), 729-741. doi: 10.1177/0265407500176002

Macy, R. J., Nurius, P. S., \& Norris, J. (2006). Responding in their best interests: Contextualizing women's coping with acquaintance sexual aggression. Violence Against Women, 12(5), 478-500. doi: 10.1177/1077801206288104

Macy, R. J., Nurius, P. S., \& Norris, J. (2007a). Latent profiles among sexual assault survivors: Implications for defensive coping and resistance. Journal of Interpersonal Violence, 22(5), 543-565. doi: 10.1177/0886260506298841

Macy, R. J., Nurius, P. S., \& Norris, J. (2007b). Latent profiles among sexual assault survivors: Understanding survivors and their assault experiences. Journal of Interpersonal Violence, 22(5), 520-542. doi: 10.1177/0886260506298839

Martin, S. L., Macy, R. J., \& Young, S. K. (2011). Health and economic consequences of sexual violence. In J. W. White, M. P. Koss \& A. E. Kazdin (Eds.), Violence against women and 
children, Vol 1: Mapping the terrain. (pp. 173-195). Washington, DC US: American Psychological Association.

Masters, N. T., Norris, J., Stoner, S. A., \& George, W. H. (2006). How does it end? Women project the outcome of a sexual assault scenario. Psychology of Women Quarterly, 30(3), 291-302. doi: 10.1111/j.1471-6402.2006.00297.x

Messman-Moore, T. L., \& Brown, A. L. (2006). Risk perception, rape, and sexual revictimization: A prospective study of college women. Psychology of Women Quarterly, 30(2), 159-172. doi: 10.1111/j.1471-6402.2006.00279.x

Messman-Moore, T. L., \& Long, P. J. (2003). The role of childhood sexual abuse sequelae in the sexual revictimization of women: An empirical review and theoretical reformulation. Clinical Psychology Review, 23(4), 537-571. doi: 10.1016/s0272-7358(02)00203-9

National Institutes of Mental Health. (2012). Statistics: Prevalence. Health Topics. Retrieved January 21, 2013, 2013, from http://www.nimh.nih.gov/statistics/index.shtml Naugle, A. E. (2000). Identifying behavioral risk factors for repeated victimization using videotaped stimulus materials. 61, ProQuest Information \& Learning, US. Retrieved from https://ezproxy.lib.uwm.edu/login?url=http://search.ebscohost.com/login.aspx?direct=tru $\mathrm{e} \& \mathrm{db}=$ psyh $\& \mathrm{AN}=2000-95016-033 \& \operatorname{login}$. asp\&site=ehost-live Available from EBSCOhost psyh database.

Noll, J. G., \& Grych, J. H. (2011). Read-react-respond: An integrative model for understanding sexual revictimization. Psychology of Violence, 1(3), 202-215. doi: 10.1037/a0023962

Norris, J., Nurius, P. S., \& Dimeff, L. A. (1996). Through her eyes: Factors affecting women's perception of and resistance to acquaintance sexual aggression threat. Psychology Of Women Quarterly, 20(1), 123-145. doi:10.1111/j.1471-6402.1996.tb00668.x 
Nurius, P. S., \& Norris, J. (1995). A cognitive ecological model of women's response to male sexual coercion in dating. Journal of Psychology \& Human Sexuality, 8(1-2), 117-139. doi: $10.1300 / J 056 \mathrm{v} 08 \mathrm{n} 01$

Nurius, P. S., Norris, J., Macy, R. J., \& Huang, B. (2004). Women's situational coping with acquaintance sexual assault: Applying an appraisal-based model. Violence Against Women, 10(5), 450-477. doi: 10.1177/1077801204264367

Nurius, P. S., Norris, J., Young, D. S., Graham, T. L., \& Gaylord, J. (2000). Interpreting and defensively responding to threat: Examining appraisals and coping with acquaintance sexual aggression. Violence and Victims, 15(2), 187-208.

Orchowski, L. M., Untied, A. S., \& Gidycz, C. A. (2012). Reducing risk for sexual Victimization. Journal of Interpersonal Violence, 27(9), 1743-1761. doi: $10.1177 / 0886260511430391$

Ozer, E. M., \& Bandura, A. (1990). Mechanisms governing empowerment effects: A selfefficacy analysis. Journal Of Personality And Social Psychology, 58(3), 472-486. doi:10.1037/0022-3514.58.3.472

Post, L. A., Biroscak, B. J., \& Barboza, G. (2011). Prevalence of sexual violence. In J. W. White, M. P. Koss \& A. E. Kazdin (Eds.), Violence against women and children, Vol 1: Mapping the terrain. (pp. 101-123). Washington, DC US: American Psychological Association.

Pumphrey-Gordon, J. E., \& Gross, A. M. (2007). Alcohol consumption and females' recognition in response to date rape risk: The role of sex-related alcohol expectancies. Journal of Family Violence, 22(6), 475-485. doi: 10.1007/s10896-007-9104-0 
Rowe, L. S., Jouriles, E. N., \& McDonald, R. (2015). Reducing sexual victimization among adolescent girls: a randomized controlled pilot trial of my voice, my choice. Behavior Therapy, 46(3), 315-27. http://doi.org/10.1016/j.beth.2014.11.003

Rozee, P. D., \& Koss, M. P. (2001). Rape: A century of resistance. Psychology of Women Quarterly, 25(4), 295-311. http://doi.org/10.1111/1471-6402.00030

Schnurr, P. P., Green, B. L., \& Kaltman, S. (2007). Trauma exposure and physical health. In M. Friedman, T. M. Keane \& P. Resick (Eds.), Handbook of PTSD: Science and Practice (pp. 406-424). New York, NY: The Guilford Press.

Senn, C. Y., Eliasziw, M., Barata, P. C., Thurston, W. E., Newby-Clark, I. R., Radtke, H. L., \& Hobden, K. L. (2015). Efficacy of a sexual assault resistance program for university women. The New England Journal of Medicine, 372(24), 2326-35. http://doi.org/10.1056/NEJMsa1411131

Thoennes, P. T. \& N. (2000). Prevalence, incidence, and consequences of violence against women. US Department of Justice Research Report. Retrieved from https://www.ncjrs.gov/pdffiles1/nij/183781.pdf

Thompson, K. M., Crosby, R. D., Wonderlich, S. A., Mitchell, J. E., Redlin, J., Demuth, G., . . Haseltine, B. (2003). Psychopathology and sexual trauma in childhood and adulthood. Journal of Traumatic Stress, 16(1), 35-38. doi: 10.1023/a:1022007327077

Turchik, J. A., \& Gidycz, C. A. (2011). Exploring the intention-behavior relationship in the prediction of sexual risk behaviors: Can it be strengthened? Journal of Sex Research, 49(1), 50-60. doi: 10.1080/00224499.2011.578220

Turchik, J. A., Probst, D. R., Chau, M., Nigoff, A., \& Gidycz, C. A. (2007). Factors predicting the type of tactics used to resist sexual assault: A prospective study of college women. 
Journal of Consulting and Clinical Psychology, 75(4), 605-614. doi: 10.1037/0022006x.75.4.605

Ullman, S. E. (2007). A 10-year update of 'review and critique of empirical studies of rape avoidance.'. Criminal Justice and Behavior, 34(3), 411-429. doi: $10.1177 / 0093854806297117$

VanZile-Tamsen, C., Testa, M., \& Livingston, J. A. (2005). The impact of sexual assault history and relationship context on appraisal of and responses to acquaintance sexual assault risk. Journal of Interpersonal Violence, 20(7), 813-32. doi:10.1177/0886260505276071

Walsh, K., DiLillo, D., \& Messman-Moore, T. L. (2012). Lifetime sexual victimization and poor risk perception: Does emotion dysregulation account for the links? Journal of Interpersonal Violence, 27(15), 3054-3071. doi: 10.1177/0886260512441081

Yeater, E. A., McFall, R. M., \& Viken, R. J. (2011). The relationship between women's response effectiveness and a history of sexual victimization. Journal of Interpersonal Violence, 26(3), 462-478. doi: 10.1177/0886260510363425

Yeater, E. A., \& Viken, R. J. (2010). Factors affecting women's response choices to dating and social situations. Journal of Interpersonal Violence, 25(8), 1411-1428. doi: $10.1177 / 0886260509354588$ 